\section{MPS II in females: molecular basis of two different cases}

EDITOR-Hunter disease or mucopolysaccharidosis type II (MPS II, MIM 309900) is an X linked recessive disease resulting from deficiency of the lysosomal enzyme iduronate-2-sulphatase (IDS, E.C.3.1.6.13). ${ }^{1}$ The IDS cDNA has been isolated ${ }^{2}$ and the genomic region containing the IDS gene and pseudogene has been completely sequenced. ${ }^{3}$ Phenotypic expression of $\mathrm{X}$ linked disorders in females may be the result of an X chromosome anomaly or homozygosity for the mutated gene, but is most frequently the result of skewed $\mathrm{X}$ chromosome inactivation. We describe two affected girls, case 1 and case 2, with a mild and a severe form of MPS II, respectively. Both have a normal karyotype but increased dermatan sulphate and heparan sulphate excretion in urine, a marked deficiency of IDS activity, and normal $\alpha$-L-iduronidase, $\beta$-Dglucuronidase, and arylsulphatase A activities in leucocytes and cultured skin fibroblasts ruling out MPS I, MPS VII, and multiple sulphatase deficiency. Molecular studies showed that case 1 is the first case of female MPS II with two mutated IDS genes and that case 2 has a de novo gene rearrangement on the paternal allele (a $3254 \mathrm{bp}$ deletion from intron 7 to intron 8 with an insertion of $20 \mathrm{bp}$ ) associated with skewed $\mathrm{X}$ inactivation of the normal maternal $\mathrm{X}$ chromosome.

Case 1 was born into a French gypsy family. At 11 years of age, she presented with hepatomegaly and growth retardation, but had no dysmorphic features, no multiplex dysostosis, no corneal clouding, no cardiovascular disease, no splenomegaly, and no mental retardation, in agreement with a mild form of MPS II.

A unique IDS transcript with a $\mathrm{T}$ to $\mathrm{C}$ substitution at cDNA position 246 in exon 2 (accession $M 38371^{2}$ ) was found in fibroblasts, changing codon CTC (leucine) to CCC (proline), L41P. Sequencing of the PCR products from intron 1 (I1.1) to intron 2 (Ex1.3') and from 5'UTR (Pro1) to intron 3 (Ex3.3') (table 1) showed only the presence of a C at the genomic DNA position 1919 in exon 2 (accession L35485). She appeared to be homozygous for this substitution after testing these two PCR products by sequencing and ASO hybridisation (table 1). The mother of case 1 was found to be a carrier of the L41P mutation.
No sample from the father was available. Experiments were conducted for checking a deletion on the paternal allele. Southern blotting of the proband's DNA did not show any gene rearrangement (results not shown). Fluorescence in situ hybridisation was performed on mitotic metaphase chromosomes from her lymphoblastoid cells (L $\beta$ ) with two probes (see legend to fig 1). Two green spots can be seen at the IDS gene locus (fig 1), excluding an IDS gene deletion on the paternal $\mathrm{X}$ chromosome. The proband's father should carry the previously undescribed L41P mutation and is probably mildly affected. In our experience, one very mildly affected grandfather was found to be a carrier of a mild mutation and remained undiagnosed until a family study (unpublished data). The high rate of consanguinity in the gypsy community could explain why both parents are carriers of this rare mutation. If the father is not a carrier, this homozygosity could be explained either by partial maternal disomy or by a de novo event. This latter hypothesis is unlikely as it would create the same rare mutation on the paternal $\mathrm{X}$ chromosome.

Normal (L41L) and mutated (L41P) cDNA was transfected into different cells, normal skin fibroblasts, L $\beta$ from an MPS II patient with a total deletion of the IDS gene (L $\beta$ del), ${ }^{4}$ and COS-7 cells. Mutant IDS L41P cDNA in pTK vector ( $p$ TK IDS) and pREP4 vector ( $p$ REP IDS) were generated as previously described. ${ }^{5}$ The sequences of the oligonucleotides (mut-L41P and mut-XhoI) are indicated in table 1 and the mutated cDNA was sequenced. L $\beta$ del and normal skin fibroblasts were transfected by electroporation with $\mathrm{pREP}$ IDS and pTK IDS respectively, as previously described. ${ }^{5}$ COS cells were transfected with pTK IDS using FuGENE ${ }^{\mathrm{TM}} 6$ (Roche). Wild type IDS cDNA and L41P mutant cDNA were transiently expressed in COS cells and normal human skin fibroblasts and stably expressed in L $\beta$ del. ${ }^{6}$

The processing of the wild type IDS protein is identical in all these cells. ${ }^{56}$ After a three hour pulse, COS cells, normal fibroblasts, and L $\beta$ del transfected with L41P mutant cDNA produced only the $76 \mathrm{kDa}$ precursor, and after a 24 hour chase, no $55 \mathrm{kDa}$ lysosomal mature form was produced in any of the different cell types expressing L41P, while the $76 \mathrm{kDa}$ polypeptide was degraded (fig 2, table 2). Expression study of the mutant cDNA (L41P) in different cell types does not explain the mild phenotype in case 1 , as no mature lysosomal IDS could be visualised (fig 2). L41P affects a highly conserved amino acid in seven of

Table 1 Primers or oligoprobes (IDS) used for PCR, sequencing, mutagenesis, or ASO hybridisation

\begin{tabular}{lll}
\hline Primers & Position (L35485) & Sequence \\
\hline PCR/sequencing & nt 1805-1824 & 5'-TCCAGCCTTGGGCCTCTTAG \\
I1.1 & nt 2087-2066 & 5'-CTCAGTGCACGAAGCAGCACA \\
Ex1.3' & nt 83-104 & 5'-GGGCTTTGTTATAGATTGATTC \\
Pro1 & nt 2940-2919 & 5'-AATGCTGGATTCAGACACCAC \\
Ex3.3' & nt 19094-19114 & 5'-GGTGGGCTCTAGGTGAACATG \\
DB5 & nt 19267-19247 & 5'-CTGGCTCCATCAACTGTGAGG \\
DB6 & nt 20075-20098 & 5'-GCATTTCAGGGACAGGTTGTACAC \\
del S & nt 20874-20861 & 5'-CAAGCTCTTGCAGTACTTCAGCAC \\
del AS & & \\
Mutagenesis & & 5'-GCTGAACGTTCTTCCCATCATCGTGGATG \\
mut-L41P & & 5'-GCTCGACGGTACTCGCGGAACTGAAAAACC \\
mut-Xho I & & \\
ASO & nt 1927-1911 & 5'-CGATGATGATGAGAAGAACG \\
L41L & nt 1927-1911 & 5'-CGATGATGATGGGAAGAACG \\
L41P &
\end{tabular}

ASO: the mutated base is in bold. 


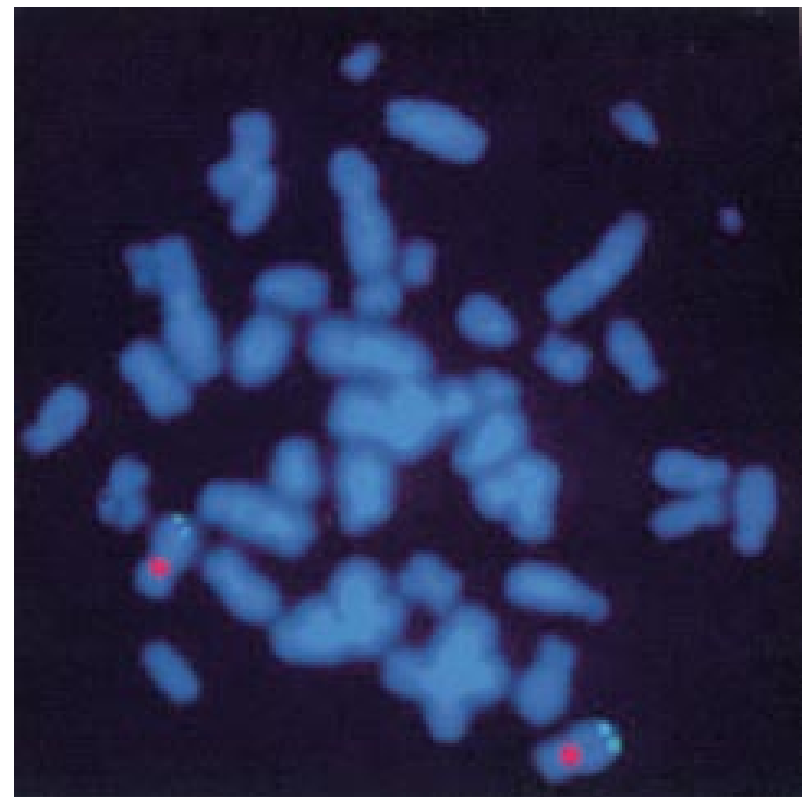

Figure 1 Fluorescence in situ hybridisation was performed on mitotic metaphase chromosomes from case $1 \mathrm{~L} \beta(n=50)$ with two probes, a cosmid containing the total IDS gene and a centromeric probe (Oncor appligene), green and red, respectively. Two green spots can be seen at the IDS gene locus, indicating the presence of two genes.

nine sulphatases ${ }^{78}$ and the mutation prevents the proper folding of IDS in an early step of the processing (no $90 \mathrm{kDa}$ form is produced).

No IDS activity was observed in L41P transfected L $\beta$ del. An increase in IDS activity was observed in COS cells and normal fibroblasts transfected by L41P, 3.8\% and $28.8 \%$ of the IDS activity produced by the wild type cDNA, respectively (table 2). This residual activity of the L41P mutation expressed in cells with a basal IDS activity (COS and normal fibroblasts) may be caused by a delayed proteolysis of the mutant precursor in the presence of the normal protein, as previously described for a $\beta-\mathrm{D}$ glucuronidase missense mutation expressed in COS cells. ${ }^{9}$ The stability of the L41P precursor may vary in the different tissues as the recognition of the misfolded polypeptide may depend on the cell types. Furthermore, a severe phenotype would be avoided if only $1 \%$ of this precursor is processed and active ${ }^{10}$ and such a low level would not be detected by our expression study experiments.

$\mathrm{X}$ inactivation study was also performed in case 1 and her mother by analysing the methylation status at three polymorphic loci, MAOA, ${ }^{11}$ HUMAR $A,{ }^{12}$ and DXS255. ${ }^{13}$ At the DXS255 locus (fig 3A), case 1's allele 1 is resistant to HhaI digestion, while her allele 2 appears almost completely digested. Fifty percent of both alleles are cut in her mother. Analysis at the MAOA and HUMARA loci confirmed these results. Thus, $\mathrm{X}$ inactivation is skewed in case 1 and random in her mother, but this mechanism is not implicated in case 1 's disease.

Case 2 was born to first cousin Tunisian parents. At the age of 3 years 6 months, she had a coarse face, hearing loss, hepatosplenomegaly, severe thoracolumbar kyphosis, limitations of joint mobility, mental retardation, and mitroaortic valvular dysplasia, but no corneal clouding. She had a severe form of the disease and died at the age of 10 years.

A unique IDS transcript with a complete deletion of exon 8, resulting in the omission of 58 of the 550 amino acids of the IDS protein, was identified in fibroblasts. The exon 8 skipping was caused by a 3254 bp deletion in genomic DNA, extending from intron 7 (nt 17419, L35485) to intron 8 (nt 20692, L35485) with an insertion of 20 nucleotides (5'-CCACACAGGCATGAGCCATG)
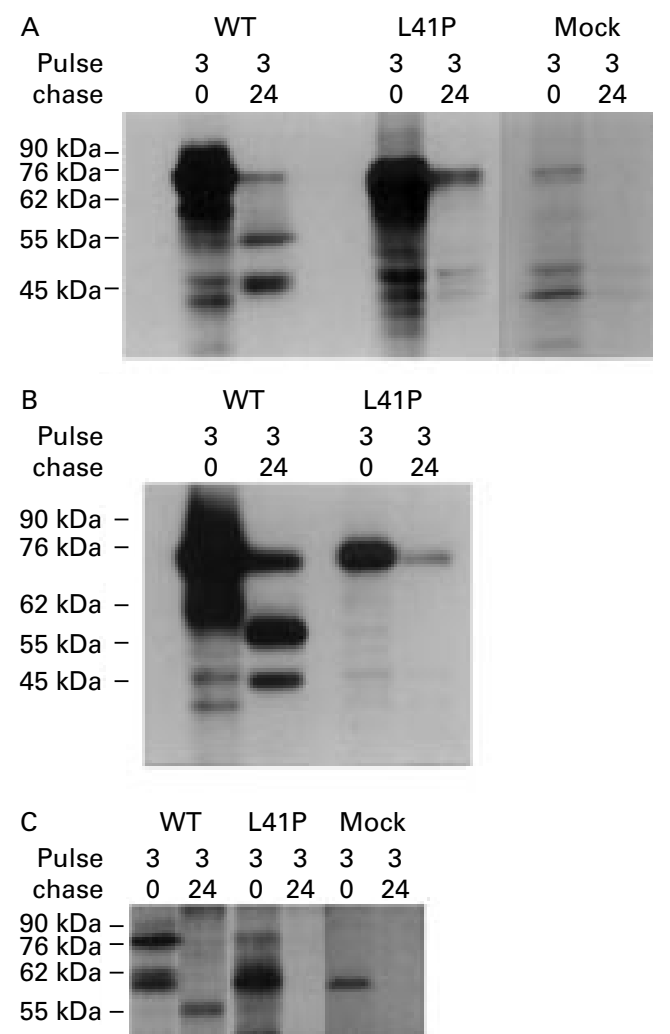

Figure $2{ }^{35} S$ pulse chase labelling of transfected cells by wild type or L41P cDNA. Molecular mass of the different IDS polypeptides ( $k D a)$ is on the left. (A) COS cells transfected by L41P cDNA showed no $90 \mathrm{kDa}$ form after a three hour labelling and no 55/45 kDa mature forms after a 24 hour pulse, in contrast to COS cells transfected by L41L cDNA. (B) $L \beta$ del transfected by $L 41 P$ cDNA produced only the unstable $76 \mathrm{kDa}$ precursor. (C) Normal skin fibroblasts transfected by L41P cDNA produced only the unstable $76 \mathrm{kDa}$ precursor.

at position 17418: 17419del3254/17418ins20. Sequence comparison showed that 12 nucleotides of this insertion belong to an $A l u$ repeat located in intron 8 at position 21573-21864. This gene rearrangement can be visualised by Southern blotting, after HindIII digestion of genomic DNA; a $12 \mathrm{~kb}$ abnormal fragment was present and case 2 was heterozygous for this deletion (fig 4). The patient was the only carrier of the 17419 del3254/17418ins 20 in her family, in agreement with the results of the enzymatic assays.

At the DXS255 locus (fig 3B), case 2's maternal allele is completely digested by $H h a \mathrm{I}$, while the paternal allele is uncut; in her mother and sister, $50 \%$ of both alleles are cut. $\mathrm{X}$ inactivation is skewed in case 2 and only the paternal $\mathrm{X}$ chromosome is active. $\mathrm{X}$ inactivation is random for her mother and her sister. The three other tested loci $(M A O A$,

Table 2 IDS activities in $\mu m o l . h^{-1} \cdot m g^{-1}$ in the different cell types transfected by the wild type cDNA (L41L), the mutant cDNA (L41P) or not transfected (NT). The basal level of IDS activity in COS cells and normal fibroblasts was subtracted

\begin{tabular}{|c|c|c|c|c|c|}
\hline & & $\begin{array}{l}\text { Activity in } \\
\mu m o l . h^{-1} \cdot m g^{-1}\end{array}$ & $76 \mathrm{kDa}$ & $90 \mathrm{kDa}$ & $\begin{array}{l}55 k D a / 45 \\
k D a\end{array}$ \\
\hline \multirow[t]{3}{*}{ Normal fib } & L41L & $4.00 \pm 1.21(\mathrm{n}=3)$ & + & + & + \\
\hline & L41P & $1.15 \pm 0.38(\mathrm{n}=3)$ & + & - & - \\
\hline & NT & $0.23 \pm 0.03(\mathrm{n}=3)$ & - & - & - \\
\hline \multirow[t]{3}{*}{$\mathrm{L} \beta$ del } & L41L & $4.83 \pm 0.12(\mathrm{n}=2)$ & + & + & + \\
\hline & L41P & $0.00(n=2)$ & + & - & - \\
\hline & NT & $0.00(\mathrm{n}=2)$ & - & - & - \\
\hline \multirow[t]{3}{*}{$\cos$} & L41L & $48.93 \pm 21.14(n=3)$ & + & + & + \\
\hline & L41P & $1.85 \pm 0.07(\mathrm{n}=3)$ & + & - & - \\
\hline & NT & $1.53 \pm 0.03(\mathrm{n}=3)$ & - & - & - \\
\hline
\end{tabular}

The presence or absence of the IDS polypeptide is indicated by + or - . 
A

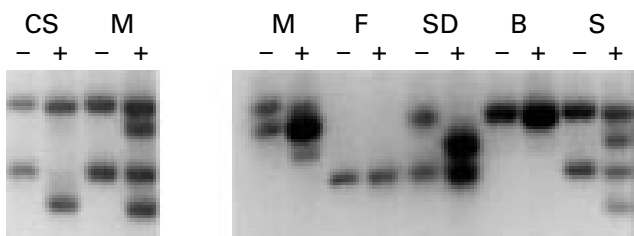

Figure $3 X$ chromosome inactivation analysis at the DXS255 locus (leucocytes). (A) Case 1 (CS) and her mother (M). (B) Case 2 (SD), her mother $(M)$, father $(F)$, brother $(B)$, and sister $(S)$. PstI digested genomic DNA (-) hybridised with the probe M27ß shows the different alleles at this locus. Additional digestion by the methylation sensitive enzyme HhaI $(+)$ allows the detection of the active allele.

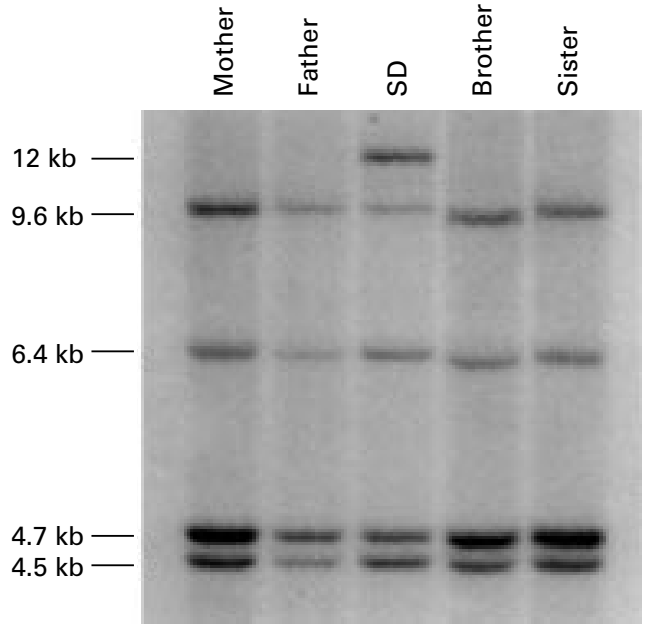

Figure 4 Southern blotting of case 2's family's genomic DNA digested by HindIII and probed with IDS CDNA. The $12 \mathrm{~kb}$ abnormal fragment is present only in case 2 (SD).

HUMARA, and FMR-1 $1^{14}$ ) confirmed these results except for the $M A O A$ locus, which was not informative for her mother. As the father does not carry the mutation in available somatic cells (leucocytes, skin fibroblasts), somatic cell hybrids with patient fibroblasts were established to check if the patient's active $\mathrm{X}$ chromosome carries the deletion.

Cell fusion of a 6-thioguanine ouabain resistant variant of Chinese hamster ovary (CHO) cells (RJK88 from Coriell Cell Repositories) with patient fibroblasts was performed with polyethylene glycol. ${ }^{15}$ Selection for hybrids was carried out by maintaining the cultures in Dubelcco's HAT-ouabain medium. The HAT-ouabain resistant clones were harvested six weeks later by scraping and expanded for DNA analysis. The RJK88-case 2 somatic cell hybrids were tested for the deletion by genomic PCR primed with DB5 (exon 8, table 1) and DB6 (exon 8, table 1) resulting in a $173 \mathrm{bp}$ fragment. These primers are included in the deletion, so no PCR product would be obtained if only the mutated allele is present. The parental origin of the $\mathrm{X}$ chromosome in hamster/human somatic hybrid clones was established by testing 15 microsatellites surrounding the IDS gene (DXS8028, DXS8045, DXS1200, DXS998, DXS8091, DXS1215, DXS1193, DXS8084, DXS8043, DXS8086, DXS8061, DXS8011, DXS8103, DXS8069, ${ }^{16}$ and DXS1113 ${ }^{17}$ ) and one intragenic StuI polymorphism (nt 20274 in intron 8, primers del S and del AS, table 1). Nine of the polymorphic markers were informative for case 2 and two were selected (DXS1113 and DXS8086) for the analysis of $\mathrm{CHO}$ patient somatic cell hybrids (X number, parental origin, and mutation). Four hamster-patient (RJK88-case 2) somatic cell hybrid clones were obtained. Two clones retained only one X chromosome of paternal origin as shown by DXS1113 and DXS8086. These two clones were carrying the complex mutation 17419del3254/ 17418ins20 (no DB5-DB6 PCR product).

Case 2 had a skewed $\mathrm{X}$ inactivation and her active $\mathrm{X}$ was carrying the severe complex mutation. This deletion appeared de novo on the paternal $\mathrm{X}$ chromosome (unaffected father, study of somatic cell hybrids) and case 2 was the only carrier in the family. She was also the only female in this family who had skewed $\mathrm{X}$ inactivation. The unbalanced $\mathrm{X}$ inactivation was probably identical in almost all her cells as she presented with a severe phenotype.

Our two female patients presented with skewed X inactivation. Plenge et $a l^{18}$ reported a heterozygous $\mathrm{C}$ to $\mathrm{G}$ mutation at position 6433 in the XIST (X inactivation specific transcript) minimal promoter (U50908) on the inactive $\mathrm{X}$ chromosome in two unrelated females with familial skewed X chromosome inactivation. They suggested that a substitution in the XIST promoter could play a role in the $\mathrm{X}$ inactivation process. The XIST promoter region from our patients was amplified and sequenced. We identified four differences from the published sequences on both chromosomes of our two patients: a $\mathrm{G}$ to $\mathrm{T}$ substitution at 6028 (U50908) and three insertions (311insT, 652insT, and 700insG: M97168). These four sequence differences were also present in all the control $\mathrm{X}$ chromosomes tested (30 normal females and 19 normal males). Thus, they were not involved in the process of $\mathrm{X}$ inactivation and probably represent sequencing errors in U50908 and M97168. Our patients were both negative for the mutation C6433G described by Plenge et $a l^{18}$ and no specific nucleotide substitution could be identified but there was no familial context of skewed $\mathrm{X}$ inactivation in these two cases.

These two MPS II affected females illustrate two different mechanisms by which females can be affected by recessive $\mathrm{X}$ linked disorders. The skewed $\mathrm{X}$ inactivation of the normal $\mathrm{X}$ chromosome in a carrier female has been documented in four other cases of MPS II, ${ }^{19}$ as in many other X linked diseases. Our patient 1 is the first case of an affected MPS II female with two mutated IDS genes. This work was supported by grants from Vaincre les Maladies Lysosomales and
Fondation pour la Recherche Médicale. We thank Professor J J Hopwood (Australia) for providing the IDS cDNA clone and K Timms (USA) for providing a cosmid containing the total IDS gene.

STÉPHANE CUDRY* ISABELLE TIGAUD + ROSELINE FROISSART ${ }^{\star}$ VÉRONIQUE BONNET* IRÈNE MAIRE* DOMINIQUE BOZON*

^Centre d'Etude des Maladies Métaboliques, Hôpital Debrousse, 69332 Lyon Cedex 05, France

†Laboratoire d'Hématologie et de Cytogénétique, Hôpital Edouard Herriot, Lyon Cedex, France

Correspondence to: Dr Cudry, bozon@cismsun.univ-lyon1.fr

1 Neufeld EF, Muenzer J. The mucopolysaccharidosis. In: Scriver CR, Beaudet AL, Sly WS, Valle D, eds. The metabolic and molecular basis of inherited disease. 7th ed. New York: McGraw-Hill, 1995:2465-94.

2 Wilson PJ, Morris CP, Anson DS, Occhiodoro T, Bielicki J, Clements PR, et al. Hunter syndrome: isolation of an iduronate-2-sulfatase cDNA clone and al. Hunter syndrome: isolation of an iduronate-2-sulfatase cDNA cl
analysis of patient DNA. Proc Natl Acad Sci USA 1990;87:8531-5.

3 Timms KM, Lu F, Shen Y, Pierson CA, Muzny DM, Gu Y, et al. $130 \mathrm{~kb}$ of Timms KM, Lu F, Shen Y, Pierson CA, Muzny DM, Gu Y, et al. $130 \mathrm{~kb}$ of
DNA sequence reveals two new genes and a regional duplication distal to the human iduronate-2-sulfate sulfatase locus. Genome Res 1995;5:71-8

4 Froissart R, Blond JL, Maire I, Guibaud P, Hopwood JJ, Mathieu M, et al. Hunter syndrome: gene deletions and rearrangements. Hum Mutat 1993;2: 138-40.

5 Millat G, Froissart R, Maire I, Bozon D. Characterization of iduronate sulphatase mutants affecting N-glycosylation sites and the cysteine-84 residue. Biochem f 1997;326:243-7.

6 Froissart R, Millat G, Mathieu M, Bozon D, Maire I. Processing of iduronate 2-sulphatase in human fibroblasts. Biochem f 1995;309:425-30.

7 Franco B, Meroni G, Parenti G, Levilliers J, Bernard L, Gebbia M, et al. A cluster of sulfatase genes on Xp22.3: mutations in chondrodysplasia punctata (CDPX) and implications for warfarin embryopathy. Cell 1995;81:1525.

8 Bond CS, Clements PR, Ashby SJ, Collyer CA, Harrop SJ, Hopwood JJ, et Bond CS, Clements PR, Ashby SJ, Collyer CA, Harrop SJ, Hopwood JJ,
al. Structure of a human lysosomal sulfatase. Structure 1997;5:277-89.

9 Wu BM, Tomatsu S, Fukuda S, Sukegawa K, Orii T, Sly WS. Overexpression rescues the mutant phenotype of L176F mutation causing 
beta-glucuronidase deficiency mucopolysaccharidosis in two Mennonite siblings. F Biol Chem 1994;269:23681-8.

10 Thomas GH. "Pseudodeficiencies" of iysosomal hydrolases. Am 7 Hum Genet 1994:54:934-40.

11 Hendriks RW, Chen ZY, Hinds H, Schuurman RK, Craig IW. An X chromosome inactivation assay based on differential methylation of a $\mathrm{CpG}$ island coupled to a VNTR polymorphism at the 5' end of the monoamine oxidase A gene. Hum Mol Genet 1992;1: 662 .

12 Allen RC, Zoghbi HY, Moseley AB, Rosenblatt HM, Belmont JW. Methylation of HpaII and HhaI sites near the polymorphic CAG repeat in the human androgen-receptor gene correlates with $\mathrm{X}$ chromosome inactivation. Am f Hum Genet 1992;51:1229-39.

13 Cachia PG, Culligan DJ, Thomas ED, Whittaker J, Jacobs A, Padua RA. Methylation of the DXS255 hypervariable locus 5' CCGG site may be affected by factors other than X inactivation status. Genomics 1992;14:704 .

14 Carrel L, Willard HF. An assay for X inactivation based on differential methylation at the fragile X locus, FMR1. Am $\mathcal{F}$ Med Genet 1996;64:27-30.
15 Davidson RL, Gerald PS. Improved techniques for the induction of mammalian cell hybridization by polyethylene glycol. Som Cell Genet 1976; 2:165-76

16 Dib C, Faure S, Fizames C, Samson D, Drouot N, Vignal A, et al. A comprehensive genetic map of the human genome based on 5,264 microsatellites. Nature 1996;380:152-4.

17 Weber C, Oudet C, Johnson S, Pilia G, Schlessinger D, Hanauer A. Dinucleotide repeat polymorphism close to IDS gene in Xq27.3-q28 (DXS1113). Hum Mol Genet 1993;2:612

18 Plenge RM, Hendrich BD, Schwartz C, Arena JF, Naumova A, Sapienza C, et al. A promoter mutation in the XIST gene in two unrelated families with skewed X-chromosome inactivation. Nat Genet 1997;17:353-6.

19 Sukegawa K, Matsuzaki T, Fukuda S, Masuno M, Fukao T, Kokuryu M, et al. Brother/sister siblings affected with Hunter disease: evidence for skewed X chromosome inactivation. Clin Genet 1998;53:96-101. 